\title{
Association of vitamin D deficiency with clinical outcomes in critically ill Korean children
}

\author{
Won Kyoung Jhang, Da Hyun Kim and Seong Jong Park ${ }^{\S}$ \\ Division of Pediatric Critical Care medicine, Department of Pediatrics, Asan Medical Center Children's Hospital, University of Ulsan College of Medicine, 88, \\ Olympic-ro-43-gil, Songpa-gu, Seoul 05505, Korea
}

BACKGROUND/OBJECTIVES: Vitamin D is a pleiotropic hormone that affects various body organ systems. We evaluated the prevalence of a vitamin D deficiency (VDD) and its potential role in the clinical condition of critically ill Korean children. SUBJECTS/METHODS: Patients under 18 years old with a $25(\mathrm{OH})$ vitamin D measurement on the first day of PICU admission were included from among the children admitted to the pediatric intensive care unit (PICU) of our tertiary children's hospital between October 2017 and January 2019.

RESULTS: A total of 172 pediatric patients were enrolled. The mean $25(\mathrm{OH})$ vitamin D level was $17.5 \pm 12.8 \mathrm{ng} / \mathrm{mL}$. There was a $65.1 \%$ prevalence of VDD $(25(\mathrm{OH})$ vitamin $\mathrm{D}$ level $<20 \mathrm{ng} / \mathrm{mL})$. VDD was associated with age at PICU admission, gastrointestinal/hepatobiliary disorders, International Society of Thrombosis and Hemostasis disseminated intravascular coagulation (ISTH DIC) score, pediatric multiple organ dysfunction syndrome (pMODS) score and with several laboratory test findings including hemoglobin, platelet, C-reactive protein, serum albumin, total bilirubin, prothrombin time, and anti-thrombin III levels. Most of these parameters also showed significant linear correlations with the $25(\mathrm{OH})$ vitamin $\mathrm{D}$ level $(P<0.05)$. However, no statistically meaningful association was found between VDD and other clinical conditions such as the need for a mechanical ventilator, requirement for vasoactive drugs, duration of the PICU and hospital stays, or PICU mortality.

CONCLUSION: There is a high prevalence of VDD in critically ill Korean children. There were significant associations between the $25(\mathrm{OH})$ vitamin $\mathrm{D}$ level and gastrointestinal/hepatobiliary disorders, the pMODS score and with coagulation related factors. Further large-scale studies with more specific subgroup analyses are required to more precisely assess the clinical implications of VDD in critically ill pediatric patients.

Nutrition Research and Practice 2020;14(1):12-19; https://doi.org/10.4162/nrp.2020.14.1.12; pISSN 1976-1457 elSSN 2005-6168

Keywords: Vitamin D, pediatrics

\section{INTRODUCTION}

Vitamin D is well known pleiotropic prohormone that plays a key role in various pathophysiologic processes and has multiple actions on various target tissues and organs in the human body. Apart from its primary influences on calcium homeostasis and bone metabolism that are required to maintain skeletal health, vitamin D also has an essential role in controlling cell differentiation, apoptosis and growth, and inflammatory, immunomodulatory and anticoagulant effects [1-6]. It thus shows associations with several clinical conditions including cardiovascular, renal, neuropsychological, infectious, immunologic, allergic, cardio-metabolic and malignant diseases [7-12].

A growing understanding of the various critical functions of vitamin $D$ has generated considerable interest in terms of the clinical implications of its deficiency, particularly in critically ill patients, and shed new light on its potential as a therapeutic target. There have therefore been various studies on the association between a low vitamin $D$ level and the severity of critical illnesses on patient admission, intensive care unit (ICU) morbidity, mortality, and the outcomes of therapeutic trials. However, the findings of prior studies of vitamin D conducted in critically ill children remain controversial [2,3,13-20]. Furthermore, there are currently no data on vitamin $D$ in relation to in critically ill Korean children.

In our present study therefore, we evaluated the prevalence of VDD and the associations between the $25(\mathrm{OH})$ vitamin D levels on admission and the clinical condition among a population of critically ill Korean children.

\section{SUBJECTS AND METHODS}

\section{Patients}

This study was approved by the institutional review board of Asan Medical Center, Seoul, Korea (IRB number: 2019-0230). The requirement for parental consent was waived due to the retrospective nature of the analyses. All children who had been consecutively admitted to the 14-bed multidisciplinary pediatric

\footnotetext{
${ }^{\S}$ Corresponding Author: Seong Jong Park, Tel. 82-2-3010-3385, Fax. 82-2-3010-6978, Email. drpsj@amc.seoul.kr

Received: April 24, 2019, Revised: June 23, 2019, Accepted: August 2, 2019

This is an Open Access article distributed under the terms of the Creative Commons Attribution Non-Commercial License (http://creativecommons.org/licenses/by-nc/3.0/) which permits unrestricted non-commercial use, distribution, and reproduction in any medium, provided the original work is properly cited.
} 
medical intensive care unit (PICU) of our children's hospital between October 2017 and January 2019 were eligible for enrollment. Among these cases, all patients under 18 years with a $25(\mathrm{OH})$ Vitamin D level measurement on the first day of PICU admission were included in the study population.

\section{Data collection}

We retrospectively reviewed the medical records and available PICU database information for each of the enrolled pediatric patients. The data collected from these records were the baseline characteristics of the subjects including weight, height, and weight for height (WFH) z score, demographic data, information on preexisting medical disorders, underlying diseases, causes of PICU admission, duration of PICU and hospital stays, need for mechanical ventilator (MV) support, duration of $\mathrm{MV}$ support, and requirement for vasoactive drugs. We calculated the body mass index (BMI) in patients aged over 2 years. From the WFH $z$ and $B M I ~ z$ scores, we defined a moderate to severe malnutrition state as a $z$ score $<-2[21,22]$.

\section{Measurement of laboratory parameters}

Blood samples had been obtained as close as possible to the time of the PICU admission in all of the study subjects and were subjected to laboratory testing including routine $\mathrm{CBC}$ levels (white blood cell [WBC], hemoglobin [Hg], platelet [plt]), chemistry profiles (albumin, creatinine [Cr],total bilirubin [tBi], lactate), $25(\mathrm{OH})$ vitamin D levels, coagulation profiles (prothrombin time $[P T]$, anti-thrombin III [AT III]), and C-reactive protein (CRP).

$\mathrm{CBC}$, routine chemistry and coagulation profiles were measured using the $\mathrm{XN}$-series instruments, c-8000 and CS-5000, respectively. The serum concentrations of $25(\mathrm{OH})$ vitamin $D$ were measured by radioimmunoassay (DIAsource $250 \mathrm{H}$ Vitamin D total--RIA--CT; DIAsource ImmunoAssays S.A., Louvain-laNeuve, Belgium) in accordance with the manufacturer's instructions.

We defined vitamin D insufficiency (VDI) as a $25(\mathrm{OH})$ vitamin D level $<30 \mathrm{ng} / \mathrm{mL}$, a vitamin D deficiency (VDD) as $10 \leq 25(\mathrm{OH})$ vitamin $\mathrm{D}<20 \mathrm{ng} / \mathrm{mL}$, and severe VDD as $25(\mathrm{OH})$ vitamin $D$ $<10 \mathrm{ng} / \mathrm{mL}$ [23-26].

To evaluate the severity of illness at the time of admission, make outcome predictions, and assess organ dysfunction, the pediatric risk of mortality (PRISM) III [27], pediatric multiple organ dysfunction syndrome (pMODS) [28] and pediatric sequential organ failure assessment (pSOFA) scores [29] were calculated using the poorest values documented within the first 24 hours after admission to the PICU. The International Society on Thrombosis and Hemostasis disseminated intravascular coagulation (ISTH DIC) score was calculated to evaluate the DIC and related clinical outcomes.

\section{Statistical analysis}

Data were statistically analyzed using the Statistical Package for Social Science (SPSS) release 21.0 for Windows (SPSS, Chicago, IL). Continuous data were expressed as the mean \pm SD or median and interquartile range, as appropriate. Categorical variables were expressed as percentages. We used the chi-square or Fisher's exact test to compare qualitative categorical variables between groups. To compare quantitative continuous variables, the two-tailed independent Student's $t$ test was used if the data were normally distributed and the Mann-Whitney nonparametric $U$ test was used if the variables demonstrated a non-normal distribution. We ran trend analysis for the two variables using a linear by linear association test. The Pearson's correlation coefficient was used in the context of normality to test univariable correlations, whereas the Spearman's $\rho$ coefficient was used for correlation testing of non-normally distributed variables. Multivariate logistic regression analysis with backward elimination was conducted using variables yielding $P$-values $<0.05$ by univariate analysis to identify independent variables associated with the outcomes. Factors considered to be confounding were entered into multivariable binary logistic regression analysis for adjustment that age, sex, body weight, ISTH DIC score, pMODS score and gastrointestinal/hepatobiliary problems were included as covariates in the model. Model fits were assessed using the Hosmer-Lemeshow goodness of fit test. A non-significant value $(P>0.05)$ for this test suggested the absence of a biased fit. Results were summarized as adjusted odds ratios and the respective $95 \%$ confidence intervals (Cls). For all analysis, variables with a two-sided $P$-value less than 0.05 were considered statistically significant.

\section{RESULTS}

Baseline characteristics of the study patients

A total of 172 critically ill children that presented at our hospital

Table 1. Baseline characteristics of the study population

\begin{tabular}{|c|c|}
\hline Variables & $\begin{array}{l}\text { Total subjects } \\
(n=172)\end{array}$ \\
\hline $\operatorname{Sex}(M: F)$ & $88: 84$ \\
\hline Age at the time of PICU admission (month) ${ }^{1)}$ & $34(1-227)$ \\
\hline Weight at the time of PICU admission $(\mathrm{kg})^{1)}$ & $11.6(2.56-109)$ \\
\hline moderate to severe malnutrition, $\mathrm{n}(\%)$ & 59 (34.3\%) \\
\hline \multicolumn{2}{|l|}{ PICU admission season, $\mathrm{n}$ (\%) } \\
\hline Winter and Spring & $95(55.2)$ \\
\hline Summer and Fall & $77(44.8)$ \\
\hline \multicolumn{2}{|l|}{ Underlying disease, n (\%) } \\
\hline Gastroenterologic/Hepatobiliary & $19(11.0)$ \\
\hline Hemato-oncologic & $37(21.5)$ \\
\hline Neurologic & $32(18.6)$ \\
\hline Cardiac & $29(16.9)$ \\
\hline Respiratory & $10(5.8)$ \\
\hline Metabolic/Endocrine & $26(15.1)$ \\
\hline \multicolumn{2}{|l|}{ Cause of PICU admission, n (\%) } \\
\hline Respiratory failure & $77(46.4)$ \\
\hline Heart failure & 20 (11.6) \\
\hline Gastrointestinal / hepatobiliary problems & $27(15.7)$ \\
\hline Use of mechanical ventilation, $\mathrm{n}$; (\%) & $95(55.2)$ \\
\hline Use of vasoactive drugs, n; (\%) & $80(47.3)$ \\
\hline Hospital day (days) ${ }^{2)}$ & $42.9 \pm 77.2$ \\
\hline PICU duration (days) ${ }^{2)}$ & $11.2 \pm 15.0$ \\
\hline Duration of MV support (days) ${ }^{2)}$ & $8.4 \pm 11.0$ \\
\hline PICU mortality (\%) & 12.2 \\
\hline WBC $\left(x \quad 10^{3} / \mu \mathrm{L}\right)^{2)}$ & $27.3 \pm 82.2$ \\
\hline $\mathrm{Hg}(\mathrm{g} / \mathrm{dL})^{2)}$ & $10.7 \pm 2.5$ \\
\hline Platelet $\left(\times 10^{3} / \mu \mathrm{L}\right)^{2)}$ & $254.9 \pm 178.3$ \\
\hline $\operatorname{CRP}(\mathrm{mg} / \mathrm{dL})^{2)}$ & $3.7 \pm 7.2$ \\
\hline
\end{tabular}


Table 1. continued

\begin{tabular}{lc}
\hline \multicolumn{1}{c}{ Variables } & $\begin{array}{c}\text { Total subjects } \\
(\mathrm{n}=172)\end{array}$ \\
\hline${\text { albumin }(\mathrm{g} / \mathrm{dL})^{2)}}^{2)}$ & $3.2 \pm 0.7$ \\
Lactate $(\mathrm{mmol} / \mathrm{L})^{2)}$ & $3.4 \pm 7.8$ \\
tBi $(\mathrm{mg} / \mathrm{dL})^{2)}$ & $1.9 \pm 4.9$ \\
PT $(\%)^{2)}$ & $64.1 \pm 25.8$ \\
ATIII $(\%)^{2)}$ & $71.0 \pm 26.1$ \\
25(OH) Vitamin D $(\mathrm{ng} / \mathrm{mL})^{2)}$ & $17.5 \pm 12.8$ \\
Vitamin D deficiency, $\mathrm{n}(\%)$ & $112(65.1)$ \\
severe vitamin D deficiency & $68(39.5)$ \\
ISTH DIC score ${ }^{2)}$ & $2.6 \pm 2.1$ \\
PRISM III score & $12.0 \pm 7.8$ \\
PSOFA score & $6.3 \pm 3.1$ \\
pMODS score & $5.1 \pm 3.0$ \\
\hline
\end{tabular}

\footnotetext{
1) Median and range (all such values)

${ }^{2)}$ Mean $\pm \mathrm{SD}$ (all such values)

$\mathrm{M}$, male; F, female; PICU, pediatric intensive care unit; $\mathrm{n}$, number; MV, mechanical ventilation; WBC, white blood cell; $\mathrm{Hg}$, hemoglobin; CRP, C-reactive peptide; $\mathrm{tBi}$, total bilirubin; PT, prothrombin time; ATIII, anti-thrombin; CRP, C-reactive peptide; RDW, red blood cell distribution width; ISTH DIC score, international society on Thrombosis and Hemostasis Disseminated intravascular coagulation score; PRISM III, pediatric risk of mortality; pSOFA, pediatric sequential organ failure assessment; pMODS, pediatric multiple organ dysfunction syndrome.
}

over a 16-month period were included in the current analysis, comprising 88 boys and 84 girls. The baseline characteristics of this study population are presented in Table 1. The median age and body weight at the time of PICU admission was 34 months (range, 1-227) and $11.6 \mathrm{~kg}$ (range, 2.56-109), respectively. The most common underlying diseases were gastrointestinal and hepatobiliary disorders (35/172, 21.2\%). Respiratory failure (77/172, 46.4\%) was the leading cause of PICU admission. The mean $25(\mathrm{OH})$ vitamin $D$ level of the enrolled patients was 17.5 $\pm 12.8 \mathrm{ng} / \mathrm{mL}$. There were 112 children in our current study population (65.1\%) with VDD. Among these patients, 68 (39.5\%) showed a $25(\mathrm{OH})$ vitamin $D$ level $<10 \mathrm{ng} / \mathrm{mL}$, indicating severe VDD. Fifty nine (34.3\%) patients were assessed as having a moderate to severe malnutrition status. The PICU mortality rate in the VDD group was $14.3 \%$, which was higher than overall PICU mortality in the total study population (12.2\%).

\section{Factors associated with VDD}

We compared the VDD and non-VDD groups (i.e. patients with a $25(\mathrm{OH})$ vitamin $\mathrm{D}$ level $>20 \mathrm{ng} / \mathrm{mL}$ ) and observed marked differences in age and weight at the time of PICU admission. In terms of laboratory findings, the hemoglobin $(\mathrm{Hg})$, platelet

Table 2. Comparisons between the VDD and non-VDD subjects

\begin{tabular}{|c|c|c|c|}
\hline Variables & $\begin{array}{c}\text { Vitamin D deficiency group } \\
(25(\mathrm{OH}) \text { vitamin } \mathrm{D}<20) \\
(\mathrm{n}=112)\end{array}$ & $\begin{array}{c}\text { Non-vitamin } D \text { deficiency group } \\
(25(\mathrm{OH}) \text { vitamin } D \geq 20) \\
(n=60)\end{array}$ & $P$-value \\
\hline Sex $(M: F)$ & $57: 55$ & $31: 29$ & 0.525 \\
\hline Age at the time of PICU admission (month) ${ }^{1)}$ & $61.0(1-227)$ & 19 (1-194) & $<0.001$ \\
\hline Weight at the time of PICU admission $(\mathrm{kg})^{1)}$ & $16.4(2.56-109)$ & $8.7(2.6-62.3)$ & 0.001 \\
\hline moderate to severe malnutrition & $37(62.7)$ & $22(37.3)$ & 0.377 \\
\hline PICU admission season, $\mathrm{n}(\%)$ & & & 0.055 \\
\hline Winter and Spring & $68(71.6)$ & $27(28.4)$ & \\
\hline Summer and Fall & $44(57.1)$ & $33(42.9)$ & \\
\hline Use of mechanical ventilation, $\mathrm{n}$; (\%) & $55(49.1)$ & $40(66.7)$ & 0.036 \\
\hline Use of vasoactive drugs, $\mathrm{n}$; (\%) & $52(47.3)$ & $28(47.5)$ & $>0.999$ \\
\hline Hospital day (days) $)^{2)}$ & $41.7 \pm 72.4$ & $44.8 \pm 84.8$ & 0.813 \\
\hline PICU duration (days) $)^{2)}$ & $10.9 \pm 16.9$ & $11.8 \pm 11.2$ & 0.728 \\
\hline Duration of MV support (days) ${ }^{2)}$ & $7.9 \pm 10.5$ & $9.0 \pm 11.9$ & 0.716 \\
\hline PICU mortality (\%) & 14.3 & 8.3 & 0.332 \\
\hline WBC $\left(\times 10^{3} / \mu \mathrm{L}\right)^{2)}$ & $28.3 \pm 82.6$ & $25.4 \pm 82.2$ & 0.827 \\
\hline $\mathrm{Hg}(\mathrm{g} / \mathrm{dL})^{2)}$ & $10.5 \pm 2.6$ & $11.2 \pm 2.0$ & 0.048 \\
\hline Platelet $\left(\times 10^{3} / \mu \mathrm{L}\right)^{2)}$ & $223.5 \pm 156.1$ & $313.6 \pm 202.1$ & 0.003 \\
\hline $\operatorname{CRP}(\mathrm{mg} / \mathrm{dL})^{2)}$ & $4.4 \pm 8.1$ & $2.2 \pm 4.8$ & 0.029 \\
\hline albumin $(g / d L)^{2}$ & $3.1 \pm 0.7$ & $3.3 \pm 0.6$ & 0.032 \\
\hline Lactate $(\mathrm{mmol} / \mathrm{L})^{2)}$ & $3.7 \pm 9.5$ & $3.0 \pm 2.7$ & 0.595 \\
\hline $\mathrm{Cr}(\mathrm{mg} / \mathrm{dL})^{2)}$ & $0.9 \pm 1.7$ & $0.7 \pm 1.3$ & 0.564 \\
\hline $\mathrm{tBi}(\mathrm{mg} / \mathrm{dL})^{2)}$ & $2.5 \pm 5.9$ & $0.8 \pm 2.0$ & 0.007 \\
\hline PT $(\%)^{2)}$ & $58.7 \pm 24.8$ & $71.2 \pm 26.1$ & 0.003 \\
\hline ATIII $(\%)^{2)}$ & $66.6 \pm 26.7$ & $79.3 \pm 23.0$ & 0.004 \\
\hline ISTH DIC score ${ }^{2)}$ & $3.0 \pm 2.1$ & $1.9 \pm 1.8$ & 0.001 \\
\hline PRISM III score ${ }^{2)}$ & $12.2 \pm 7.8$ & $11.7 \pm 7.9$ & 0.653 \\
\hline pSOFA score ${ }^{2)}$ & $6.5 \pm 3.2$ & $6.0 \pm 3.0$ & 0.339 \\
\hline pMODS score ${ }^{2)}$ & $5.4 \pm 3.0$ & $4.4 \pm 2.8$ & 0.035 \\
\hline
\end{tabular}

\footnotetext{
${ }^{1)}$ Median and range (all such values)
}

${ }^{2)}$ Mean $\pm \mathrm{SD}$ (all such values)

M, male; F, female; PICU, pediatric intensive care unit; n, number; MV, mechanical ventilation; WBC, white blood cell; Hg, hemoglobin; CRP, C-reactive peptide; Cr, creatinine; tBi, total bilirubin; PT, prothrombin time; ATIII, anti-thrombin; ISTH DIC score, international society on Thrombosis and Hemostasis Disseminated intravascular coagulation score; PRISM III, pediatric risk of mortality; pSOFA, pediatric sequential organ failure assessment; pMODS, pediatric multiple organ dysfunction syndrome. 
Table 3. Spearman's rho coefficients for the $25(\mathrm{OH})$ vitamin $\mathrm{D}$ levels and other indicated parameters

\begin{tabular}{|c|c|c|c|c|c|c|c|c|}
\hline & $\mathrm{Hg}$ & plt & CRP & $\mathrm{tBI}$ & PT sec & ATIII & ISTH DIC score & pMODS \\
\hline rho coefficients & $0.162^{*}$ & $0.206^{*}$ & $-0.268^{*}$ & $-0.355^{*}$ & $-0.333^{*}$ & $0.291^{*}$ & $-0.310^{*}$ & $-0.205^{* *}$ \\
\hline$P$-value & 0.034 & 0.007 & 0.000 & 0.000 & 0.000 & 0.000 & 0.000 & 0.007 \\
\hline
\end{tabular}

$\mathrm{Hg}$, hemoglobin; plt, platelet; CRP, C-reactive peptide; tBi, total bilirubin; PT, prothrombin time; ATIII, anti-thrombin; ISTH DIC score, International Society on Thrombosis and Hemostasis disseminated intravascular coagulation score; pMODS, pediatric multiple organ dysfunction syndrome.

Table 4. Multivariate logistic regression analysis of VDD

\begin{tabular}{|c|c|c|c|c|}
\hline Covariate $^{1)}$ & Unadjusted OR $(95 \% \mathrm{Cl})$ & $P$-value & Adjusted OR $(95 \% \mathrm{Cl})$ & $P$-value \\
\hline Age (months) & $1.009(1.004-1.015)$ & 0.001 & $1.010(1.004-1.016)$ & 0.001 \\
\hline ISTH DIC score & $1.319(1.113-1.563)$ & 0.001 & $1.231(1.021-1.484)$ & 0.029 \\
\hline pMODS score & $1.124(1.006-1.257)$ & 0.040 & $1.108(0.980-1.254)$ & 0.102 \\
\hline Gastrointestinal/hepatobiliary problems & $7.909(1.800-34.747)$ & 0.006 & $6.452(1.412-29.476)$ & 0.016 \\
\hline
\end{tabular}

ISTH, International Society on Thrombosis and Hemostasis; DIC, disseminated intravascular coagulation; pMODS, pediatric multiple organ dysfunction syndrome; Cl, confidence interval.

1) Sex and body weight included as covariates in the model.

(A) $\left(\times 10^{3} / \mathrm{uL}\right)$

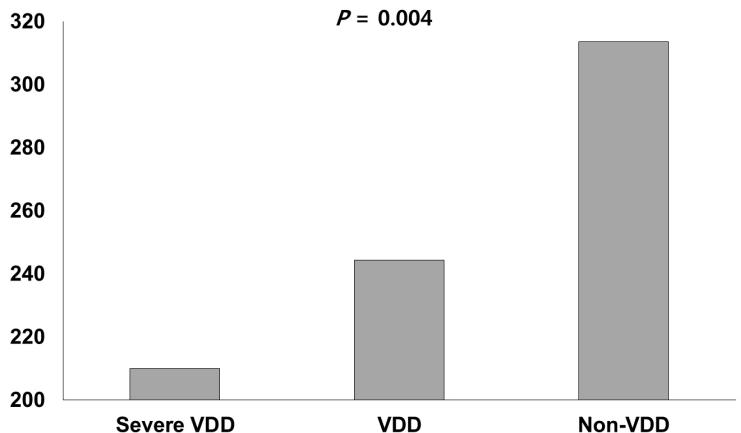

(C)

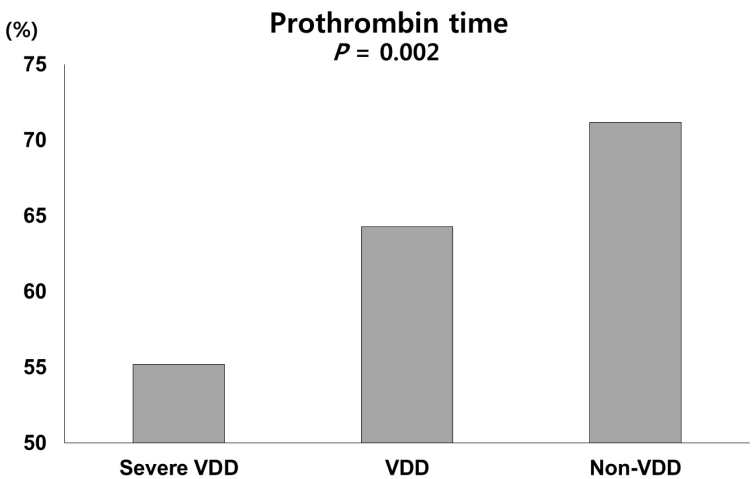

(E)

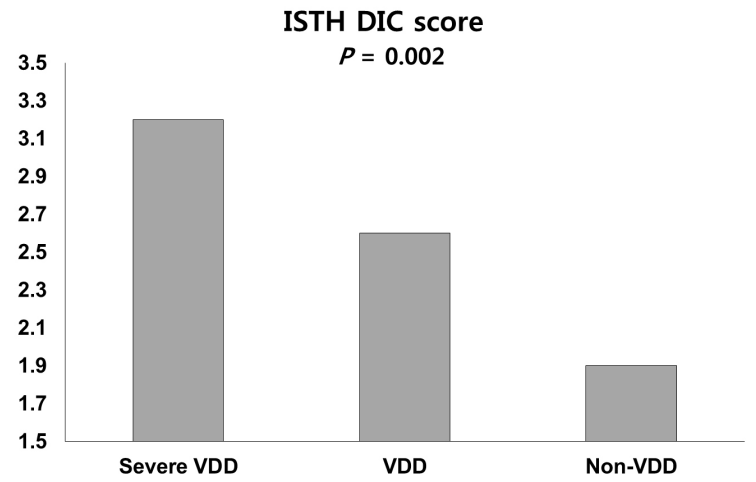

(B)

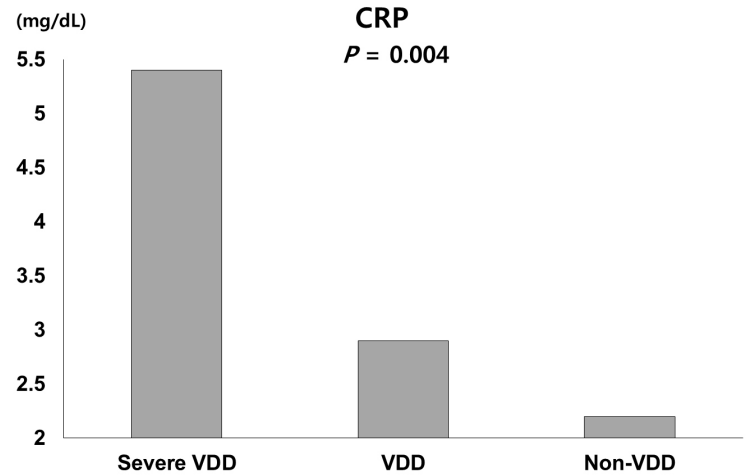

(D)

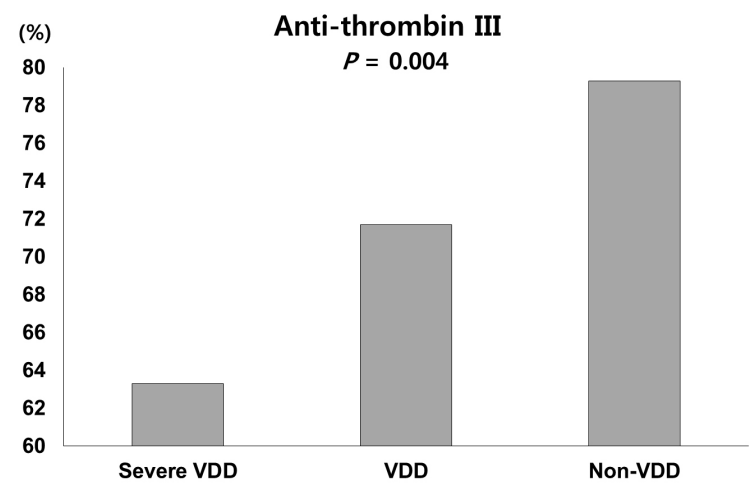

(F)

pMODS score

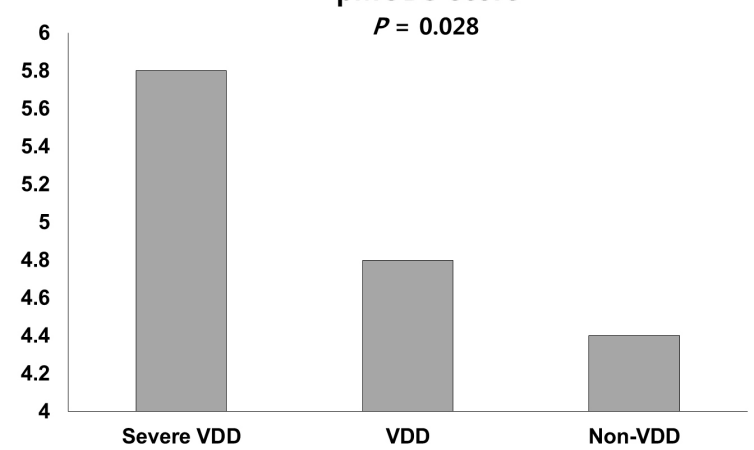

Fig. 1. Comparisons of the mean values for several parameters among the severe VDD, VDD and non-VDD groups. VDD, vitamin D deficiency; CRP, C-reactive peptide: ISTH DIC score, International Society on Thrombosis and Hemostasis disseminated intravascular coagulation score; pMODS, pediatric multiple organ dysfunction syndrome. 
(plt), CRP, serum albumin, total bilirubin (tBi), prothrombin time (PT) and anti-thrombin III (AT III), coagulation related parameters showed a significant association with VDD, as indicated in Table 2. These parameters also showed a statistically significant correlation with the $25(\mathrm{OH})$ vitamin D level (Table 3). Among the severity evaluation scores, the ISTH DIC and pMODS showed a statistically meaningful association with VDD. As the $25(\mathrm{OH})$ vitamin D level lowered, the plt, CRP, PT, AT III, ISTH DIC score and MODS score had a tendency to increase (Fig. 1). In line with these observations, several laboratory values, particularly coagulation-related parameters, demonstrated a meaningful association with VDD, which also had a tendency to show a linear association with the $25(\mathrm{OH})$ vitamin $D$ level i.e. the severity of the deficiency.

We found no definitive association in our current study series between the presence of VDD and seasonal variations in the PICU admission, the nutritional status of the child including moderate to severe malnutrition, requirement for MV support or vasoactive drug use, the duration of the PICU or hospital stay, or PICU mortality. By multivariate logistic regression analysis, the age at PICU admission, gastrointestinal/hepatobiliary problems, and the ISTH DIC and pMODS score were independently significantly associated with VDD (Table 4).

\section{DISCUSSION}

Our current analyses have identified a far higher prevalence of VDD (65.1\%) in critically ill Korean children than has been previously reported in other populations $[17,20,26,30]$. The pathophysiology and causes of VDD are probably multifactorial and quite complex. Previously reported risk factors for VDD include breastfed infants, living at high altitudes because of limited UV light exposure, dark skin and a high BMI due to a supposed sequestration of dietary vitamin $D$ in the adipose tissue $[2,24]$. In addition, the prevalence of VDD can vary by geographical location, ethnicity, dietary habit, body composition and by different combinations of clinical comorbidities [23].

Our present analyses have revealed a statistically significant association between VDD and age, with a tendency toward an increased incidence with age. These findings are consistent with previous data showing that adolescent patients have a lower serum vitamin D level than younger patients [26,31].

As vitamin $D$ is mainly directly synthesized by UV irradiation of the skin (>90\%), several factors associated with this cutaneous synthesis were suggested as risk factors for VDD.One of these is seasonal variations in the serum vitamin D levels $[14,32,33]$. In our current study, VDD was found to be more prevalent in patients admitted during the colder seasons, but this was not statistically significant. Seasonal variation implies the contribution of sunlight exposure, which is affected by duration and intensity. This is also impacted by latitude, clothing, outdoor activity, use of sunscreen, and others [34,35]. We could not collect data on all of these factors in our current study. In addition, critically ill children may have limited opportunities to play outside or do outdoor activities compared to normal healthy children, which may be a potential confounding factor in relation to our present results.

Skin color is also known to be related to the cutaneous synthesis of vitamin D. Although there is still some controversy around this, darker skin has been reported to require more sun light to synthesize vitamin D than lighter skin and VDD is suggested to be more common in dark skinned populations [36-38].

In terms of ethnicity, as well as skin color, different types of clothing based on cultural backgrounds, dietary habits (lower intake of dairy products or other foods fortified with vitamin D), different vitamin D metabolism, the serum level of vitamin $\mathrm{D}$ binding protein (VDBP) and the varying prevalence of genetic polymorphisms could affect the vitamin D levels [39,40]. We included only Korean children in our current study series, among which the VDD prevalence could well be different to other ethnic populations.

The nutritional status of the patients, including overweight or moderate to severe malnutrition, was also not found to be significantly associated with VDD in this study.

As the concentration of $25(\mathrm{OH})$ vitamin $D$ is 1000 -fold higher than that of $1,25(\mathrm{OH})$ vitamin $D$ in plasma, and its half- life (nearly 2-3 weeks) is much longer than that of 1,25 (OH) vitamin D (only 4-24 hours), it is widely accepted that the $25(\mathrm{OH})$ vitamin $D$ level better reflects the vitamin $D$ status $[7,41,42]$. We thus evaluated VDD via the measurement of $25(\mathrm{OH})$ vitamin $D$ in our current analysis. However, more than $85 \%$ of the $25(\mathrm{OH})$ vitamin $\mathrm{D}$ in serum is bound to VDBP, whilst $10-15 \%$ is bound to albumin and less than $1 \%$ is in a free state in the plasma [43]. As a consequence, the serum albumin level can affect the serum $25(\mathrm{OH})$ vitamin $D$ level as shown by our present findings.

In our present analyses also, gastrointestinal/hepatobiliary problems showed significant associations with VDD. Although our pediatric series was very heterogeneous and included patients such as biliary atresia, varix bleeding, malnutrition, fulminant hepatitis and hepatic failure, all of these disorders could affect serum $25(\mathrm{OH})$ vitamin D levels by affecting dietary vitamin $D$ absorption from the intestine or suppressing the hepatic function of vitamin D metabolism causing increases in its circulating form, and in the production of vitamin $D$ carrier proteins, albumin and VDBP $[36,44,45]$.

In addition, there is growing interest in the genetic influences on the metabolism, transport, and binding of vitamin $D$ to VDBP, and the vitamin D receptor, which may also influence the plasma vitamin D level and the prevalence of VDD [46-49]. Inherent differences in the serum vitamin $D$ level should therefore not be overlooked in future studies of VDD.

In our current study series, the most remarkable findings were the prominent correlation between the vitamin $D$ levels in the severely ill children and several coagulation-related factors and the ISTH DIC score. These results are consistent with previous reports on the anti-coagulant properties of vitamin D. Recently, there has been growing evidence for the adverse effects of VDD on coagulation, fibrinolysis and inflammation in numerous in vitro and animal studies, and in human studies. Vitamin $D$ is a known potent inhibitor of anti- $32 \mathrm{GPI}$ antibody-mediated tissue factor expression in endothelial cells [50], which can influence the coagulation system. The clinical implications of this include a possible association with ischemic heart diseases, deep vein thrombosis, or other thrombogenic disorders $[5,51,52]$. Although these clinical conditions appear not to be 
as prevalent in pediatric patients, many other disorders including severe sepsis, infection, inflammation and malignancies are common in critically ill children and could result in the activation of coagulation. A strong and systemic activation of coagulation combined with the inhibition of physiological anticoagulant and fibrinolytic systems could lead to intravascular fibrin formation and consumption of procoagulants. The most severe disorder resulting from an imbalance of these systems is known as disseminated intravascular coagulation (DIC), which may contribute to multiple organ failure. In our present study; as we observed a significant correlation between the serum $25(\mathrm{OH})$ vitamin $\mathrm{D}$ level and coagulation related factors, we calculated the ISTH DIC score and also found a significant association. Furthermore, the CRP and pMODS score also showed a statistically significant association with the $25(\mathrm{OH})$ vitamin $\mathrm{D}$ level in our current study population. Consistent with previous findings, the explanation for this may be that VDD is associated with inflammation, coagulation and related organ dysfunction. In addition, as vitamin D plays various roles through its receptors in as many as 30 different tissue and cell types in humans such as brain, heart, gonads, muscle, mononuclear cells, breast, prostate, small intestine, activated $\mathrm{T}$ and B lymphocytes [53], it could impact multiple bodily functions in many different ways. VDD could thus be associated with multiple organ dysfunctions that have a direct impact on PICU outcomes including morbidity, mortality and prognosis. Notably however, we did not find a significant correlation between VDD and the duration of MV support, the length of the PICU or hospital stay, or PICU mortality.

Our present study had several limitations of note. First, the subjects were all from a single tertiary children's hospital and included only critically ill pediatric patients who had been admitted over a 16 month period. This restricted the sample size and observation time, which prevented us from conducting more detailed subgroup analysis. In addition, we could necessarily only establish associations and not causality. Second, there had been no pre-illness or pre-admission vitamin $D$ level measurements in our study population. This lack of a sequential evaluation of the vitamin D levels weakened any conclusions about VDD in terms of causality and clinical outcomes. There were also few precise data on nutrition or previous vitamin supplementation in the children. This also limited any meaningful assessment of serial changes in the vitamin $D$ level. Third, blood samples for serum $25(\mathrm{OH})$ vitamin D evaluations were taken once only at the time of PICU admission, which could also have affected the results. Various genetic factors that were not assessed by our analysis but could have affected the vitamin $D$ data also cannot be ignored.

Notwithstanding the aforementioned limitations, our present analyses had several notable strengths. To our knowledge, our current study is the first report to evaluate the prevalence of VDD and its associations with several clinical outcomes in critically ill Korean pediatric patients. As previously mentioned, as the serum vitamin $D$ level can be influenced by ethnic differences, it could be meaningful to obtain baseline data for these Korean critically ill pediatric patients. As this was a single center study, the PICU management protocols were consistent across the study population, which reduces the possibility of confounding effects that could be present in a multicenter study.

In conclusion, there is a high prevalence of VDD in critically ill Korean children and there are significant associations between this condition and various clinical parameters, most notably gastrointestinal/hepatobiliary disorders, coagulation related factors, and the ISTH DIC score. Further large-scale studies aimed at understanding the complex pathophysiology of VDD and its association with critical illnesses and clinical outcomes are warranted.

\section{CONFLICT OF INTEREST}

The authors declare no potential conflicts of interests.

\section{ORCID}

Won Kyoung Jhang: https://orcid.org/0000-0003-0250-2381

Da Hyun Kim: https://orcid.org/0000-0002-8588-7848

Seong Jong Park: https://orcid.org/0000-0003-2309-0494

\section{REFERENCES}

1. Kim SY. The pleiomorphic actions of vitamin $D$ and its importance for children. Ann Pediatr Endocrinol Metab 2013;18:45-54.

2. Massey K, Dickerson R, Brown R. A review of vitamin D deficiency in the critical care population. Pharmacy 2014;2:40-9.

3. Misra M, Pacaud D, Petryk A, Collett-Solberg PF, Kappy M; Drug and Therapeutics Committee of the Lawson Wilkins Pediatric Endocrine Society. Vitamin D deficiency in children and its management: review of current knowledge and recommendations. Pediatrics 2008;122:398-417.

4. Walker VP, Modlin RL. The vitamin D connection to pediatric infections and immune function. Pediatr Res 2009;65:106R-113R.

5. Banerjee A, Khemka VK. Augmentation of anticoagulant effect with vitamin D: possible therapeutic target for venous thromboembolism. Int J Hematol Blo Dis 2017;2:1-5.

6. Kamen DL, Tangpricha V. Vitamin D and molecular actions on the immune system: modulation of innate and autoimmunity. J Mol Med (Berl) 2010;88:441-50.

7. Kaur G, Singh J, Kumar J. Vitamin D and cardiovascular disease in chronic kidney disease. Pediatr Nephrol. Forthcoming 2018.

8. Hirschler V, Molinari C, Maccallini G, Intersimone P, Gonzalez CD. Vitamin $D$ levels and cardiometabolic markers in indigenous argentinean children living at different altitudes. Glob Pediatr Health 2019;6:2333794X18821942.

9. Holick MF. Vitamin D: importance in the prevention of cancers, type 1 diabetes, heart disease, and osteoporosis. Am J Clin Nutr 2004;79: 362-71.

10. Helou M, Ning Y, Yang S, Irvine P, Bachmann LM, Godder K, Massey G. Vitamin d deficiency in children with cancer. J Pediatr Hematol Oncol 2014;36:212-7.

11. McNally JD, Leis K, Matheson LA, Karuananyake C, Sankaran K, Rosenberg AM. Vitamin $D$ deficiency in young children with severe acute lower respiratory infection. Pediatr Pulmonol 2009;44:981-8.

12. Koven NS, Cadden MH, Murali S, Ross MK. Vitamin D and long-term memory in multiple sclerosis. Cogn Behav Neurol 2013;26:155-60.

13. Braun AB, Gibbons FK, Litonjua AA, Giovannucci E, Christopher KB. 
Low serum 25-hydroxyvitamin $D$ at critical care initiation is associated with increased mortality. Crit Care Med 2012;40:63-72.

14. Amrein K, Zajic P, Schnedl C, Waltensdorfer A, Fruhwald S, Holl A, Purkart T, Wünsch G, Valentin T, Grisold A, Stojakovic T, Amrein $\mathrm{S}$, Pieber TR, Dobnig H. Vitamin D status and its association with season, hospital and sepsis mortality in critical illness. Crit Care 2014;18:R47.

15. Cecchi A, Bonizzoli M, Douar S, Mangini M, Paladini S, Gazzini B, Degl'Innocenti $S$, Linden $M$, Zagli G, Peris A. Vitamin D deficiency in septic patients at ICU admission is not a mortality predictor. Minerva Anestesiol 2011;77:1184-9.

16. Sankar J, Lotha W, Ismail J, Anubhuti C, Meena RS, Sankar MJ. Vitamin $D$ deficiency and length of pediatric intensive care unit stay: a prospective observational study. Ann Intensive Care 2016;6:3.

17. Ponnarmeni $S$, Kumar Angurana S, Singhi S, Bansal A, Dayal D, Kaur R, Patial A, Verma Attri S. Vitamin D deficiency in critically ill children with sepsis. Paediatr Int Child Health 2016;36:15-21.

18. McNally JD, Menon K, Lawson ML, Williams K, Doherty DR. 1,25-Dihydroxyvitamin $D$ levels in pediatric intensive care units: risk factors and association with clinical course. J Clin Endocrinol Metab 2015;100:2942-5.

19. Sankar J, Ismail J, Das R, Dev N, Chitkara A, Sankar MJ. Effect of severe vitamin $\mathrm{D}$ deficiency at admission on shock reversal in children with septic shock: a prospective observational study. J Intensive Care Med 2019;34:397-403.

20. McNally JD, Nama N, O'Hearn K, Sampson M, Amrein K, lliriani K, McIntyre L, Fergusson D, Menon K. Vitamin D deficiency in critically ill children: a systematic review and meta-analysis. Crit Care 2017;21:287.

21. Becker P, Carney LN, Corkins MR, Monczka J, Smith E, Smith SE, Spear BA, White JV; Academy of Nutrition and Dietetics; American Society for Parenteral and Enteral Nutrition. Consensus statement of the Academy of Nutrition and Dietetics/American Society for Parenteral and Enteral Nutrition: indicators recommended for the identification and documentation of pediatric malnutrition (undernutrition). Nutr Clin Pract 2015;30:147-61.

22. Mehta NM, Corkins MR, Lyman B, Malone A, Goday PS, Carney LN, Monczka JL, Plogsted SW, Schwenk WF; American Society for Parenteral and Enteral Nutrition Board of Directors. Defining pediatric malnutrition: a paradigm shift toward etiology-related definitions. JPEN J Parenter Enteral Nutr 2013;37:460-81.

23. Holick MF. Vitamin D deficiency. N Engl J Med 2007;357:266-81.

24. Holick MF, Binkley NC, Bischoff-Ferrari HA, Gordon CM, Hanley DA, Heaney RP, Murad MH, Weaver CM; Endocrine Society. Evaluation, treatment, and prevention of vitamin $\mathrm{D}$ deficiency: an Endocrine Society clinical practice guideline. J Clin Endocrinol Metab 2011;96: 1911-30.

25. Rusińska A, Płudowski P, Walczak M, Borszewska-Kornacka MK, Bossowski A, Chlebna-Sokół D, Czech-Kowalska J, Dobrzańska A, Franek E, Helwich E, Jackowska T, Kalina MA, Konstantynowicz J, Książyk J, Lewiński A, Łukaszkiewicz J, Marcinowska-Suchowierska E, Mazur A, Michałus I, Peregud-Pogorzelski J, Romanowska H, Ruchała M, Socha $P$, Szalecki M, Wielgoś M, Zwolińska D, Zygmunt A. Vitamin $D$ supplementation guidelines for general population and groups at risk of vitamin D deficiency in Poland-recommendations of the Polish Society of Pediatric Endocrinology and Diabetes and the Expert Panel With Participation of National Specialist Consultants and Representatives of Scientific Societies-2018 update. Front
Endocrinol (Lausanne) 2018;9:246.

26. Madden K, Feldman HA, Smith EM, Gordon CM, Keisling SM, Sullivan RM, Hollis BW, Agan AA, Randolph AG. Vitamin D deficiency in critically ill children. Pediatrics 2012;130:421-8.

27. Pollack MM, Patel KM, Ruttimann UE. PRISM III: an updated Pediatric Risk of Mortality score. Crit Care Med 1996;24:743-52.

28. Graciano AL, Balko JA, Rahn DS, Ahmad N, Giroir BP. The Pediatric Multiple Organ Dysfunction Score (P-MODS): development and validation of an objective scale to measure the severity of multiple organ dysfunction in critically ill children. Crit Care Med 2005;33: 1484-91.

29. Matics TJ, Sanchez-Pinto LN. Adaptation and validation of a pediatric sequential organ failure assessment score and evaluation of the sepsis-3 definitions in critically ill children. JAMA Pediatr 2017;171:e172352.

30. Rippel C, South M, Butt WW, Shekerdemian LS. Vitamin D status in critically ill children. Intensive Care Med 2012;38:2055-62.

31. Mansbach JM, Ginde AA, Camargo CA Jr. Serum 25-hydroxyvitamin $D$ levels among US children aged 1 to 11 years: do children need more vitamin D? Pediatrics 2009;124:1404-10.

32. Levis S, Gomez A, Jimenez C, Veras L, Ma F, Lai S, Hollis B, Roos $B A$. Vitamin d deficiency and seasonal variation in an adult South Florida population. J Clin Endocrinol Metab 2005;90:1557-62.

33. Hebbar KB, Wittkamp M, Alvarez JA, McCracken CE, Tangpricha V. Vitamin $D$ deficiency in pediatric critical illness. J Clin Transl Endocrinol 2014;1:170-5.

34. Kimlin MG, Lucas RM, Harrison SL, van der Mei I, Armstrong BK, Whiteman DC, Kricker A, Nowak M, Brodie AM, Sun J. The contributions of solar ultraviolet radiation exposure and other determinants to serum 25-hydroxyvitamin $D$ concentrations in Australian adults: the AusD Study. Am J Epidemiol 2014;179:864-74.

35. Al-Othman A, Al-Musharaf S, Al-Daghri NM, Krishnaswamy S, Yusuf DS, Alkharfy KM, Al-Saleh Y, Al-Attas OS, Alokail MS, Moharram O, Sabico S, Chrousos GP. Effect of physical activity and sun exposure on vitamin D status of Saudi children and adolescents. BMC Pediatr 2012;12:92.

36. Holick MF, Chen TC, Lu Z, Sauter E. Vitamin D and skin physiology: a D-lightful story. J Bone Miner Res 2007;22 Suppl 2:V28-33.

37. Weishaar T, Rajan S, Keller B. Probability of vitamin D deficiency by body weight and race/ethnicity. J Am Board Fam Med 2016;29: 226-32.

38. Mostafa WZ, Hegazy RA. Vitamin D and the skin: focus on a complex relationship: a review. J Adv Res 2015;6:793-804.

39. Newton DA, Baatz JE, Kindy MS, Gattoni-Celli S, Shary JR, Hollis BW, Wagner CL. Vitamin D binding protein polymorphisms significantly impact vitamin D status in children. Pediatr Res. Forthcoming 2019.

40. Powe $C E$, Evans $M K$, Wenger J, Zonderman $A B$, Berg $A H$, Nalls $M$, Tamez H, Zhang D, Bhan I, Karumanchi SA, Powe NR, Thadhani R. Vitamin D-binding protein and vitamin $D$ status of black Americans and white Americans. N Engl J Med 2013;369:1991-2000.

41. Jones G. Pharmacokinetics of vitamin D toxicity. Am J Clin Nutr 2008;88:582S-6S.

42. Abou-Zahr R, Kandil SB. A pediatric critical care perspective on vitamin D. Pediatr Res 2015;77:164-7.

43. Bikle DD, Gee E, Halloran B, Kowalski MA, Ryzen E, Haddad JG. Assessment of the free fraction of 25-hydroxyvitamin $D$ in serum and its regulation by albumin and the vitamin D-binding protein. J Clin Endocrinol Metab 1986;63:954-9. 
44. Iruzubieta P, Terán Á, Crespo J, Fábrega E. Vitamin D deficiency in chronic liver disease. World J Hepatol 2014;6:901-15.

45. Langer-Gould A, Lucas RM, Xiang AH, Wu J, Chen LH, Gonzales E, Haraszti S, Smith JB, Quach $\mathrm{H}$, Barcellos LF. Vitamin D-binding protein polymorphisms, 25-hydroxyvitamin $D$, sunshine and multiple sclerosis. Nutrients 2018;10:E184.

46. Wang TJ, Zhang F, Richards JB, Kestenbaum B, van Meurs JB, Berry D, Kiel DP, Streeten EA, Ohlsson C, Koller DL, Peltonen L, Cooper JD, O'Reilly PF, Houston DK, Glazer NL, Vandenput L, Peacock M, Shi J, Rivadeneira F, McCarthy Ml, Anneli P, de Boer IH, Mangino M, Kato B, Smyth DJ, Booth SL, Jacques PF, Burke GL, Goodarzi $M$, Cheung CL, Wolf M, Rice K, Goltzman D, Hidiroglou N, Ladouceur M, Wareham NJ, Hocking $U$, Hart D, Arden NK, Cooper C, Malik $S$, Fraser WD, Hartikainen AL, Zhai G, Macdonald HM, Forouhi NG, Loos RJ, Reid DM, Hakim A, Dennison E, Liu Y, Power C, Stevens $\mathrm{HE}$, Jaana L, Vasan RS, Soranzo N, Bojunga J, Psaty BM, Lorentzon M, Foroud T, Harris TB, Hofman A, Jansson JO, Cauley JA, Uitterlinden AG, Gibson $Q$, Järvelin MR, Karasik D, Siscovick DS, Econs MJ, Kritchevsky SB, Florez JC, Todd JA, Dupuis J, Hyppönen $E$, Spector TD. Common genetic determinants of vitamin D insufficiency: a genome-wide association study. Lancet 2010;376:180-8.

47. Bahrami A, Sadeghnia HR, Tabatabaeizadeh SA, Bahrami-Taghanaki H, Behboodi N, Esmaeili H, Ferns GA, Mobarhan MG, Avan A. Genetic and epigenetic factors influencing vitamin D status. J Cell Physiol
2018;233:4033-43.

48. Ahn J, Yu K, Stolzenberg-Solomon R, Simon KC, McCullough ML, Gallicchio L, Jacobs EJ, Ascherio A, Helzlsouer K, Jacobs KB, Li Q, Weinstein SJ, Purdue M, Virtamo J, Horst R, Wheeler W, Chanock S, Hunter DJ, Hayes RB, Kraft P, Albanes D. Genome-wide association study of circulating vitamin D levels. Hum Mol Genet 2010;19: 2739-45.

49. Moy KA, Mondul AM, Zhang H, Weinstein SJ, Wheeler W, Chung CC, Männistö S, Yu K, Chanock SJ, Albanes D. Genome-wide association study of circulating vitamin D-binding protein. Am J Clin Nutr 2014;99:1424-31.

50. Agmon-Levin N, Blank M, Zandman-Goddard G, Orbach H, Meroni PL, Tincani A, Doria A, Cervera R, Miesbach W, Stojanovich L, Barak V, Porat-Katz BS, Amital H, Shoenfeld Y. Vitamin D: an instrumental factor in the anti-phospholipid syndrome by inhibition of tissue factor expression. Ann Rheum Dis 2011;70:145-50.

51. Targher G, Pichiri I, Lippi G. Vitamin D, thrombosis, and hemostasis: more than skin deep. Semin Thromb Hemost 2012;38:114-24.

52. Elbers LP, Wijnberge M, Meijers JC, Poland DC, Brandjes DP, Fliers $E$, Gerdes VE. Coagulation and fibrinolysis in hyperparathyroidism secondary to vitamin D deficiency. Endocr Connect 2018;7:325-33.

53. Lee JY, So TY, Thackray J. A review on vitamin d deficiency treatment in pediatric patients. J Pediatr Pharmacol Ther 2013;18: 277-91. 